\title{
Formação, competência e cidadania
}

\author{
Julieta Beatriz Ramos Desaulniers *
}

RESUMO: O artigo refere-se às novas exigências impostas ao conjunto de iniciativas voltadas à formação do trabalhador e do cidadão, devido às transformações que vêm ocorrendo no mundo atual. Por isso, verifica-se um deslocamento de noções: - dos saberes à competência, na esfera educativa; - da qualificação à competência, na esfera do trabalho. A abordagem de tais categorias de análise, baseia-se em recentes estudos e pesquisas sobre formação, construção da competência e possíveis articulações com o aprofundamento da cidadania

Palavras-chave: Formação, competência, cidadania

Introdução

As transformações que vêm ocorrendo no mundo contemporâneo, em conseqüência do aprimoramento acentuado da tecnologia, exigem que os processos de formação sejam inovados, em especial aqueles que se vinculam ao sistema educacional do país, a fim de possibilitarem a construção da competência junto aos seus formandos. Em face da importância desse empreendimento para a sociedade como um todo, é urgente a elaboração de estudos que permitam uma maior compreensão de tal fenômeno, ao caracterizar as principais dimensões que o configuram, destacando que esse processo tende a ampliar os espaços voltados à cidadania.

* Professora do IFCH com Mestrado em Serviço Social / PUCRS. E-mail: julietard@music. pucrs.br 
Em outros termos, a Sociologia da Educação está sendo "diretamente interpelada pelas transformações estruturais, que se referem às instâncias de produção/difusão dos conhecimentos e às relações dos grupos sociais aos saberes". ${ }^{1}$

Nessa perspectiva, o presente trabalho visa apresentar alguns elementos sobre a referida questão, tendo como pressuposto que as possibilidades de construção da competência em instituição educacional estão diretamente associadas à dinâmica estrutural do campo educativo articulado, ao mesmo tempo, de forma interativa e conflitiva, com a dinâmica estrutural dos demais campos que constituem o espaço social.

\section{Em decorrência disso, supõe-se que:}

- a competência, como uma categoria de análise construída socialmente, condensa elementos significativos do desenvolvimento capitalista ocorrido nas últimas décadas, em especial no tocante às alterações que resultam em deslocamento de noções: dos saberes à competência, na esfera educativa; da qualificação à competência, na esfera do trabalho;

- ao considerar os deslocamentos de tais noções, é importante destacar que a construção da competência baseia-se nos saberes que constituem a qualificação profissional, o que não significa que sejam equivalentes entre si ou que a instauração e/ou o aprofundamento desses processos não possam ocorrer de modo simultâneo, desde que o "saber-fazer" seja superado pelo "saber-ser", como expressão da capacidade de articular inúmeros saberes em face dos desafios encontrados no mundo do trabalho, sendo mensurável pelos seus resultados;

- a produção de saberes de cunho científico sobre competência, com o intuito de evidenciar como vem ocorrendo a configuração desse fenômeno junto à realidade brasileira nas esferas do trabalho e da formação, possibilita a identificação de seus principais elementos, os quais são indispensáveis às iniciativas de instituições que visam desencadear esse processo, minimizando o risco de incorrerem em meras transposições de modelos construídos em outras bases culturais;

- o processo de construção da competência, ao se basear em habilidades que envolvem todas as dimensões do indivíduo - com ênfase na capacidade de crítica e de autonomia, no espírito de iniciativa com audácia, na responsabilidade e na flexibilidade em face da mudança e do inu- 
sitado, além de uma visão de empreendedor -, implica rupturas tanto na dinâmica interna dos espaços institucionais voltados a esse tipo de formação, como também na própria dinâmica dos demais espaços sociais em que esse indivíduo atua como cidadão. Tais rupturas tendem a produzir novas possibilidades à construção da cidadania.

A seguir, pretendo demonstrar o que foi exposto anteriormente com base em discussões e estudos bastante recentes, os quais já acumulam saberes importantes sobre essa problemática, pois foram produzidos em contextos onde as novas exigências impostas ao mundo da formação pela dinâmica do sistema capitalista já ocorrem há algumas décadas. Também, apresento algumas considerações finais com o intuito de salientar certos elementos a serem incluídos na objetivação da dinâmica institucional, que visem instaurar o processo de construção da competência.

\section{0 deslocamento de noções}

A preocupação com o conteúdo/sentido dos termos não representa um mero preciosismo, especialmente quando os mesmos se constituem em categorias de pensamento que exprimem o tempo comum de um grupo, sendo indispensáveis para a comunicação e coordenação das atividades de seus membros. Por isso, são comparáveis a uma ferramenta (capital material acumulado), tendo ambas - categoria e ferramenta - um parentesco com a instituição social. ${ }^{2}$

Nas últimas décadas, verifica-se o surgimento de novos termos para expressar algumas das novas exigências do capitalismo. Junto à esfera do trabalho, a qualificação é substituída pela noção de competência, e na esfera educativa, a instauração de saberes é englobada pela construção da competência.

É certo que, nos países que ocupam uma posição central na dinâmica do sistema capitalista, esse deslocamento de noções já conta com algumas décadas e, por isso, verifica-se uma definição relativamente clara dos significados que a categoria competência está a resumir, assim como formação e qualificação. ${ }^{3}$

De acordo com os vários estudos e pesquisas produzidos em tais países:

- a formação é entendida "como um processo que, na maioria das vezes, insere-se num sistema formal de escolarização, tendo como fi- 
nalidade preparar os indivíduos para o trabalho; - a qualificação realizase também em processos de formação, e estando sempre relacionada com um "um sistema de exigências, ligado ao emprego e às aquisições individuais, oriundas da experiência (obtida no/pelo trabalho) e da formação"; - a competência relaciona-se com a capacidade de mobilizar conhecimentos/saberes junto aos postos de trabalho, os quais são adquiridos através da formação, da qualificação e da experiência social. Essa noção baseia-se, fundamentalmente, nos resultados. ${ }^{5}$

O que se verifica é que a constante recomposição dos saberes, imposta aos trabalhadores pelo ritmo das mudanças sociais, econômicas e tecnológicas, está implicando também na inclusão de saberes que não estão diretamente ligados aos postos de trabalho.

Isso está fazendo com que o "lugar da qualificação propriamente dita (saber-fazer)" seja ocupado pela competência, onde o saber assume uma atribuição de sujeito e "a relação cognitiva tende a definir-se sobre o modo de ser (ser competente) e não mais sobre aquele de ter (ter um saber com o risco de perdê-lo) uma qualificação". '

Competência "é uma noção carrefur", envolvendo várias esferas sociais e, por isso, ela favorece utilizações e interesses diversos, às vezes opostos entre si. Em parte, essa sua plasticidade é um indicador "da força social que possui, devido às idéias que veicula". 8

\section{Da qualificação à competência}

Por um longo período enfatizou-se o "fazer" e mascarou-se o "saber", mesmo se este tenha sempre sido expropriado do trabalhador pelo capital. ${ }^{9}$ Atualmente, com a globalização da economia, o desenvolvimento de todas as capacidades do trabalhador como um ser integral constituise numa das condições ao avanço dessa nova ordem social.

$E$, nesse sentido, estudos têm demonstrado que a economia tem crescido em produtividade "não tanto em função do aumento quantitativo de capital e trabalho, como ocorria nos primórdios da industrialização, mas como resultado da combinação mais eficiente dos fatores no processo de produção, fatores esses definidos como a influência crescente da ciência, da tecnologia, da qualificação da força de trabalho e da eficácia da gestão do processo produtivo". ${ }^{10}$ 
Em face dessa realidade, enquanto o mundo do trabalho defrontase com as orientações que configuram a Qualidade Total (TCQ), que se efetiva através de um controle rigoroso da organização do processo de trabalho e da gestão, baseada numa metodologia que se apóia nos resultados das organizações junto ao mercado, o mundo da formação está impelido a produzir/formar o trabalhador que corresponda a tais exigências.

A desarticulação que caracteriza esses dois mundos, mais ou menos acentuada dependendo da época, constitui-se hoje em um obstáculo a essa nova dinâmica imposta pelo avanço do capitalismo, tanto para o capital como também para o trabalho. E, nesse contexto, a produção de trabalhadores com uma nova "performance" exige estratégias de cunho pedagógico, que sejam devidamente planejadas, pois não há mais como esperar por aquela competência produzida naturalmente, de forma espontânea como, em geral, vinha acontecendo até bem pouco tempo.

Os países que ocupam uma posição central no capitalismo defrontam-se com essa situação desde a década 1970. Nesse período, seus trabalhadores já contavam com um nível de qualificação (saber-fazer) bastante satisfatório, o que lhes permitiu implementar programas mais amplos de formação contínua e, a partir da década de 1990, alguns desses países, em forma de lei, ${ }^{11}$ lançaram o plano de construção da competência.

Essa não é a realidade dos países que ocupam uma posição mais periférica nesse sistema, o que se constitui num duplo desafio: ampliar as ações voltadas à qualificação que, ao mesmo tempo, contemplem os pressupostos que configuram a formação que visa instaurar a competência junto aos seus formandos.

Tal empreendimento envolve rupturas, junto às instituições que se dedicam à formação, que sejam capazes de ampliar os "espaços de possibilidades" para permitir a operacionalização dessa nova forma de formar o trabalhador. E o êxito de tais intervenções está, em parte, associado à compreensão relativa ao significado de qualificação e de competência, como expressões que condensam diferentes aspectos da sociedade atual. ${ }^{12}$

É certo que a construção da competência baseia-se nos diversos saberes que constituem a qualificação. Todavia, mesmo com a multiqualificação, não está segurado o desempenho profissional que o mundo do trabalho vem exigindo, o qual se traduz pela competência e não pela qualificação ou multiqualificação.

Competência refere-se a "um sistema de conhecimentos, conceituais e processuais, organizados em esquemas operatórios que per- 
mitem, no interior de uma família de situações, a identificação de uma ação eficaz"...."Competência integra os conhecimentos sobre objetos e ação", representando um dos princípios organizadores da formação. ${ }^{13}$

Competência é inseparável da ação, e os conhecimentos teóricos e/ou técnicos são utilizados de acordo com a capacidade de executar as decisões que ela (a ação) sugere. Ou seja, competência é a capacidade de resolver uma problema em uma situação dada. A competência baseia-se nos resultados. ${ }^{14}$

Conforme Trépos "as competências são mobilizadas, principalmente, quando se trata de fazer a prova daquilo que se sabe, face uma situação dada e que se sabe fazer bem. São empreendidas por uma pessoa ao desempenhar um trabalho/uma tarefa, quando aí surge um problema. As bases em que as competências se fundam relacionam-se com a mobilização de um conjunto muito mais diversificado de objetos que o da qualificação". ${ }^{15}$

Os conceitos dos vários autores apresentados anteriormente insistem que a construção da competência supõe todos os tipos de saberes (formais, informais, teóricos, práticos/da experiência, sociais...), ${ }^{16}$ desde que sejam articulados de maneira eficaz, em face dos desafios encontrados no posto de trabalho. Desse modo, espera-se que o novo interesse ou o novo mito do capital em relação ao mundo do trabalho, que é o da fábrica sem pane, ${ }^{17}$ tenha maiores condições de concretizar-se.

Isso implica ações pedagógicas que enfatizem aqueles objetivos que desenvolvem as habilidades que configuram a "performance" do trabalhador, considerada como a expressão de competência. Em geral, as habilidades privilegiadas nesses processos de formação, em países desenvolvidos, insistem na capacidade de crítica e de autonomia, na responsabilidade e flexibilidade em face da mudança e do inusitado, no espírito de iniciativa com audácia, além de uma visão de empreendedor.

\section{Construção da competência e da cidadania}

É evidente que as rupturas que têm caracterizado a realidade dos últimos tempos não significam mudança no paradigma que a fundamenta. Sendo assim, é a ordem capitalista que continua vigorando. Todavia, como uma dinâmica que é produzida dialeticamente - num movimento 
que envolve conflito e contradição, conservadorismo, inovação e transformação -, esse sistema dispõe, também, de espaços para a construção da cidadania ao se instaurar a competência, mesmo se é uma demanda produzida principalmente pelo capital para atender às necessidades do mundo do trabalho.

Parece óbvio que um trabalhador, formado com base nas habilidades mencionadas anteriormente, torna-se competente (porque, ao articular saberes em face dos problemas encontrados em seu trabalho, atua criticamente, evidenciando autonomia e responsabilidade, tendo visão de conjunto, lançando proposições novas), não só no e/pelo seu espaço de trabalho, mas também em todas as esferas sociais em que atua como cidadão. Isso é inevitável, visto que tal processo de formação fundamenta-se na construção de identidades sociais, envolvendo o indivíduo como um todo e, assim, atinge seu ser rompendo então com as delimitações impostas pelo mero fazer.

É claro que implementar ações e estratégias com essa perspectiva pedagógica supõe uma avaliação junto às instituições que pretendem responder às novas exigências do mundo do trabalho e, ao mesmo tempo, resgatar todas as possibilidades desse processo. É importante que tal avaliação sustente-se em pressupostos científicos, para atingir uma objetivação da realidade que é, afinal, "a prova que justifica o empreendimento com vistas às inovações necessárias à construção de competências". ${ }^{18}$

Tal exigência deve-se ao intenso aprimoramento da tecnologia, o qual não tolera mais a improvisação. Assim, a ciência - conhecimento construído - passa a desempenhar um papel fundamental na construção de competências, mesmo se o seu princípio está na experiência e na ação.

Por isso, os cientistas têm nesse contexto um papel muito importante a desempenhar, ampliando sua própria competência ao produzir estudos e pesquisas que objetivem o grau de articulação entre as principais exigências do mundo do trabalho, com as iniciativas propostas até o momento pelas instituições ligadas à esfera educativa.

Desse modo, a construção da competência constitui-se numa estratégia também voltada ao desenvolvimento e à consolidação da cidadania, visto que o planejamento desses processos pedagógicos - por se basear numa realidade objetivada, através de instrumentos elaborados com 0 auxílio dos saberes científicos já existentes - possibilita a definição de metas que priorizam as dimensões que configuram as especificidades dessas esferas educativas. 
Dessa forma, rompe-se com a implantação de modelos que não estão preocupados em operacionalizar as necessidades do contexto cultural em que tais processos estão inseridos, resultando numa formação bastante deficitária. Além disso, por não estarem preenchendo sequer os requisitos da qualificação (saber-fazer), estão impelidos, pelo ritmo das mudanças que lhes atingem diretamente, a buscar soluções adequadas e rápidas para sanar suas atuais deficiências. Somente assim, a construção de competências tem condições de assumir a devida importância junto aos espaços que se dedicam à formação.

Essa é a saída para a maioria das instituições educacionais desse país, a fim de não se tornarem inviáveis conforme critérios de julgamento do próprio mercado, dada a desarticulação com o mundo do trabalho, mesmo se este tem sido a razão primeira da formação, desde o advento do capitalismo industrial.

Afora a reprovação do mercado, devido à incapacidade de certas instituições educacionais de produzir as condições necessárias para operacionalizar as demandas do mundo do trabalho - a formação do trabalhador competente -, vale considerar a possível reprovação da própria sociedade como um todo, já que tais esferas deixam, assim, de cumprir com uma das funções básicas, que é a formação do cidadão.

$\mathrm{E}$, desse modo, esvai-se uma oportunidade ímpar na história, pois a lógica da competência tem condições de trazer "algo novo se ela conduzir a um reconhecimento daquilo que constrói a experiência e daquilo que faz seu valor, a sua importância social". ${ }^{19}$

\section{Algumas considerações finais}

A construção da competência, conforme o próprio termo construção expressa, depende de intervenções pedagógicas instauradas em instituições voltadas à formação, que sejam devidamente planejadas com base em uma avaliação sistemática capaz de diagnosticar as principais dimensões que caracterizam tais realidades, a fim de se atingir as principais metas que englobam a dinâmica de tal processo.

É importante que o instrumental utilizado para diagnosticar as instituições, que se decidem pela implementação dos pressupostos relativos à construção da competência, inclua itens que permitam cap- 
turar a dinâmica estrutural do campo educativo do qual elas fazem parte e sua articulação, ao mesmo tempo interativa e conflitiva, com a dinâmica estrutural dos demais campos do espaço social.

Com base nas informações obtidas com o diagnóstico da instituição definem-se as estratégias referentes à implementação de um processo voltado à construção da competência, bem como as metas a serem atingidas e a respectiva operacionalização das mesmas, expressas em ações/práticas, devidamente situadas no tempo e no espaço.

Todo esse processo baseia-se num sistema de avaliação em que se mensuram principalmente as habilidades que constituem a "performance" de um desempenho pautado pela competência, além de controlar as atividades ligadas às bases administrativas, pedagógicas e materiais como suportes indispensáveis para o sucesso desse tipo de empreendimento.

A seguir, menciono alguns procedimentos de cunho pedagógico, que são necessários ao se desencadear a construção de competências, ${ }^{20}$ com o intuito de sugerir alguns indicadores para se operacionalizar as habilidades que configuram tal processo:

- definir, o mais precisamente possível, o perfil do profissional a ser formado, que envolva o conjunto de suas dimensões como um ser integral;

- instaurar estratégias de aprendizagem que se vinculam ao conjunto de conhecimentos já acumulados pelo formando, a partir de situações-problema a serem resolvidas por ele. Assim, é possível desafiálo a aplicar, da forma mais articulada possível, todos os inúmeros saberes que ele dispõe até o momento;

- articular teoria e prática, o que supõe uma revisão do senso comum sobre a relação entre conhecimento científico e prática. Essa postura repousa na idéia de que os conhecimentos não se apóiam só nos saberes disciplinares, e menos ainda, nos conhecimentos técnicos;

- propor uma dinâmica que envolva as qualidades humanas, a formação técnico-científica com instrumentos especializados confiáveis, devidamente ratificados pela ciência, a qual desempenha um papel decisivo/fundamental no desenvolvimento da competência. ${ }^{21}$

- priorizar as propostas educativas de cunho interdisciplinar, com o intuito de instaurar uma visão mais globalizante do real, que seja capaz de combater a da fragmentação; 
- insistir em relações baseadas na interação e flexibilidade entre os vários agentes que atuam na construção desse processo;

Enfim, construir competências implica o planejamento de situações suficientemente desafiadoras, a ponto de produzirem um estado, um clima de instigação/investigação junto ao formando; que as ações pedagógicas sustentem-se em problemáticas que contenham/desvelem/impliquem, tenham outras problemáticas nelas imbricadas, capazes de despertar o contínuo interesse do formando pela descoberta, pelo novo, pelo inusitado. Ou seja, pela busca de maior compreensão sobre a complexidade que constitui o real e, assim, tenha condições de interagir com ele com mais eficácia: com competência, como trabalhador e cidadão.

As considerações apresentadas aqui baseiam-se no fato de que a realidade é construída pelas ações dos indivíduos, as quais contam com uma maior ou menor pressão das estruturas socias materializadas nas várias instituições que produzem o social.

Sendo assim, e partindo do pressuposto que a instituição ${ }^{22}$ constitui-se de um conjunto de relações sociais que se desenvolve a partir de uma base material e de gestão, fica impossível falar de qualquer fenômeno de caráter institucional sem identificar, caracterizar e analisar as posições e tomadas de posição dos membros que nela atuam.

Nessa medida, toda instituição só existe através e pelas ações desencadeadas pelos seus integrantes, que são aqueles que a edificam, atribuindo-Ihe, ao mesmo tempo, uma identidade. Logo, ao se aceitarem esses pressupostos, tem que se aceitar também que os agentes sociais ligados aos processos que visam formar o trabalhador/cidadão são, também, cúmplices dessa trajetória/história.

Em outros termos, para respondermos a essa cumplicidade com base numa atuação que evidencie competência, vale adotar algumas das idéias de grandes pensadores como Braudel e Febvre, procurando colocá-las em prática. Postulam "que o homem faz a história, mas para fazê-la sem tantos riscos, para que ele, de fato, a construa (e não seja levado de roldão), precisa estar atento à parte da história que o faz. Ele deverá considerar, nessa história que o faz, seus múltiplos tempos, suas resistências e, sobretudo, deve abordá-la mais como um estatístico do que como profeta, deve mais prever do que profetizar". ${ }^{23}$ 
Notas

1. Dandurand, P. \& Ollivier, Émile. Centralité des savoirs et éducation: vers de nouvelles problématiques. In: Revue Sociologie et Société, vol. XXIII, № 1, 1991, vol. XXIII, p.3.

2. Durkheim, Émile. As formas elementares da vida religiosa. São Paulo, Paulinas, 1989, pp. 39 e 49.

3. Mais detalhes sobre o significado de tais termos, consultar Desaulniers, Julieta B. Ramos. "Formação, ou qualificação, ou competência ?" In: Revista Véritas, Porto Alegre, Edipucrs, vol. 38, № 149, mar.1993, pp. 95-103.

4. Dubar, Claude. La qualification à travers les journées de Nantes. In: Revue de Sociologie du Travail. Paris, Gauthier-Villars, № 1, 1987, p. 6.

5. Esses comentários referem-se, principalmente, às idéias de Stroobants, M. desenvolvidas em várias de suas obras. Dentre elas, cita-se: - "Qualifications ou compétences?" Communication au Symposium Formation-Travail. Travailformation, Rifret, Sherbroocke, set. 1991a (mimeo); -"Travail et compétences: récapitulation critique des approches des savoirs au travail." In: Revue Formation/Emploi. Paris, La Documentation Française, №. 33, 1991b.

6. Stroobants, op. Cit., 1991b, p. 36.

7. Idem, p. 36.

8. Tanguy, Lucie \& Ropé, Françoise. Savoirs et compétences - de l'usage de ces notions dans l'école et l'entreprise. Paris. L'Harmattan, 1994, p. 14.

9. Stroobants, op. cit., 1991b, pp. 1-2.

10. Castells, Manuel. A economia informacional, a nova divisão internacional do trabalho e o projeto socialista. Caderno CHR, Salvador, no 17, 1992. In: Fartes, Vera L. B. Modernização tecnológica e formação para o trabalho. Boletim Técnico do Senac. Rio de Janeiro, № 20(2), maio/ago. 1994, p. 3.

11. Na França, por exemplo, que tem "uma posição pioneira em matéria de direito do trabalho, a lei sobre essa questão foi emitida em 31/12/1991 (J.O. de 04/ 01/1992). Circular de 19/03/1993, do Ministério do Trabalho". In: Pacteau, Chantal. Comment mesurer les compétences? Revue Sciences Humaines, Paris, no 35, jan. 1994.

12. Essa idéia é bastante enfatizada por Tanguy, além de outros autores. Ver Tanguy, L. \& Ropé, F., op. cit., p. 52.

13. Trépos, Jean-Yves. Sociologie de la compétence profissionnelle. Nancy, PUN, 1992, p. 13.

14. Tanguy, L. \& Ropé, F., op. cit., p. 14. 
15. Trépos, op. cit., p. 16.

16. Dentre os autores que abordam esse assunto, destacam-se: Jean-Claude Forquin, Pierre Dandurand, Claude Lessard, Maurice Tardif, Tanguy, Lucie.

17. Esse mito substitui o da fábrica sem operários, conforme Stroobants, op. cit., 1991b, p. 2.

18. Darré, Jean-Pierre. "Les voies de construction d'un référenciel : Le cas des conseillers techniques agricoles." In: Tanguy, L. \& Ropé, F., op. cit., p. 161.

19. Darré, op. cit., p. 168.

20. Essas considerações baseiam-se em estudos e pesquisas que analisam esse fenômeno, verificado já há algumas décadas, em países do Primeiro Mundo. Como dimensões de uma categoria - a competência - que é construída socialmente, a partir dos mesmos pressupostos que sustentam o capitalismo, elas são válidas também à nossa realidade de país periférico. Disso é impossível livrar-se, pelo menos a curto e médio prazos, o que não implica negar suas especificidades, definidas inclusive com base na posição que ocupa nesse contexto de globalização da economia, as quais estão materializadas nas várias instituições sociais.

21. Vale lembrar aqui os comentários de Dandurand \& Ollivier, op. cit., p. 9, ao salientarem a centralidade dos saberes científicos à dinâmica capitalista, os quais se desenvolvem ao se romper com a cultura sustentada nos postulados de "um conhecimento resultante de uma mistura de fé, de verdade revelada e de filosofia escolástica". Nesse sentido, tal ruptura está por se consolidar no Brasil, pois suas bases culturais contam ainda com fortes resquícios do que constitui a cultura da cristandade e mesmo da aristocracia. Isso significa um obstáculo ao desenvolvimento da racionalidade em que se baseia o avanço do capitalismo e, em conseqüência disso, a produção de saberes de cunhos científicos fica bastante restringida, emperrando o avanço da ciência que, dada a realidade contraditória em que é produzida, não só atende aos interesses do capital, mas, ao mesmo tempo, amplia as condições de desenvolvimento do homem como cidadão.

22. A concepção dessa categoria é analisada detalhadamente num dos estudos de Chapoulie, J.-M. \& Briand, J.-P. A instituição escolar e a escolarização: Uma visão de conjunto. In: Revista Educação \& Sociedade, Campinas, Papirus \& Cedes, no 47, abr.1994, pp. 11-60 (Trad. de Desaulniers, Julieta B. Ramos).

23. In: Reis, José Carlos. Tempo, história e evasão. Campinas, Papirus, 1994, p. 179.

\section{Formation, competence and citizenship}

ABSTRACT: The article discusses the new demands imposed on a set of initiatives linked to the formation of both the worker and the 
citizen, as a result of the transformations that have been occurring in the present world. Therefore, one observes a shift of conceptions: - from knowledge to competence, in the sphere of education; - from qualification to competence, in the sphere of work. The approach of such categories of analysis is based on recent studies and research on formation, construction of competence and possible articulations of these phenomena with the enhancement of citizenship. 